\title{
Negotiating hospital infections: The debate between ecological balance and eradication strategies in British hospitals, 1947-1969
}

\section{Flurin Condrau (*) and Robert G. W. Kirk (**)}

$\left({ }^{*}\right)$ University of Zurich, Switzerland.

$\left(^{* *}\right)$ University of Manchester, UK.

Dynamis

[0211-9536] 2011; 31 (2): 385-405
Fecha de recepción: 30 de diciembre de 2010

Fecha de aceptación: 3 de febrero de 2011

SUMMARY: 1.-Introduction. 2.-From the hospital environment to the healthy carrier. 3.-Conceptualising the control of hospital infections 4.-Conclusion.

ABSTRACT: This paper reviews and contrasts two strategies of infection control that emerged in response to the growing use of antibiotics within British hospitals, c.1946-1969. At this time, we argue, the hospital became an arena within which representatives of the medical sciences and clinical practices contested not so much the content of knowledge but the way that knowledge translated into practice. Key to our story are the conceptual assumptions about antibiotics put forward by clinicians, on the one hand, and microbiologists on the other. The former embraced antibiotics as the latest weapon in their fight to eradicate disease. For clinicians, the use of antibiotics were utilised within a conceptual frame that prioritised the value of the individual patient before them. Microbiologists, in contrast, understood antibiotics quite differently. They adopted a complex understanding of the way antibiotics functioned within the hospital environment that emphasised the relational and ecological aspects of their use. Despite their broader environmental focus, microbiologists focus on the ways in which bacteria travelled led to ever greater emphasis to be placed on the "healthy» body which, having been exposed to antibiotics, became a dangerous carrier of resistant staphylococcal strains. The surrounding debate regarding the appropriate use of antibiotics reveals the complex relationship between hospital, the medical sciences and clinical practice. We conclude that the history of hospital infections invites a more fundamental reflection on global hospital cultures, antibiotic prescription practices, and the fostering of an interdisciplinary spirit among the professional groups living and working in the hospital.

KEYWORDS: Hospital infection, antibiotics, resistance, ecology, epidemiology.

PALABRAS CLAVE: Infección hospitalaria, antibióticos, resistencia, ecología, epidemiología. 


\section{Introduction $(*)$}

In the 2005 parliamentary election campaign, then conservative party leader Michael Howard put hospital infections to the front of his policy announcements regarding the future of the National Health Service. He labelled hospital infections such as MRSA the «New British disease» and promised to clean up hospitals once and for all should his party get the opportunity to form a government ${ }^{1}$. In the UK, this election campaign represents the culmination of a new political interest in hospital infections, which were, as a phenomenon, of course not new at all. The new political discussion, public concerns and the media representation of the problem centred on hospital hygiene and responsibility. Dirty wards, the new managerial culture in hospital governance, and an increasingly chaotic reform cycle that had begun in 1974, it seemed, had brought about a vicious onslaught of new regulations and infections that needed, quite literally, cleaning up. It is worth noting that this political interest in MRSA has been hugely influential in shaping the public perception of the problem of hospital infections, which is focused on individual risk and the political responsibility for conditions within the $\mathrm{NHS}^{2}$. This debate is an obvious anchor-point for wider concerns about hospital governance and the health service in Britain, but also has interesting repercussions for this article, which seeks to further understand the historicity of nosocomial infections.

It is revealing to note that it appears that contemporary public discussion and the historical work about hospital infections share a common interest in the relation between hygiene and infection. Hospitals and the dangers of infectious diseases have been regarded as intimately connected ever since the idea of using hospitals to provide medical care became popular ${ }^{3}$. Widely associated with Florence Nightingale, the hospital reform debate of

$\left({ }^{*}\right)$ The research for this article was supported by the Wellcome Trust Strategic Award in the History of Medicine at the Centre for the History of Science, Technology and Medicine, University of Manchester. We thank participants of conference sessions in Glasgow and Madrid as well as the editors and the anonymous reviewers of Dynamis for helpful comments.

1. Howard, Michael. My mother-in-law was killed by this. We need action, not words. The Independent, 7 Dec 2004.

2. Washer, Peter; Joffe, Helena. The «hospital superbug»: Social representations of MRSA. Social Science \& Medicine. 2006; 63: 2141-2152.

3. Selwyn, Sidney. Hospital infection. The first 2500 years. Journal of Hospital Infection. 1991; 18: 5-64; Ayliffe, Graham A. J.; English, Mary P., eds. Hospital infection. From miasmas to MRSA. Cambridge: Cambridge University Press; 2003. 
the 1860s emphasised the need to clean up hospitals in order to prevent regular, deadly outbreaks of infectious diseases ${ }^{4}$. When Nightingale wrote those famous lines: «It may seem a strange principle to enunciate as the very first requirement in a hospital that it should do the sick no harm», she conceptualised the problem of infections in hospitals as an environmental concern $^{5}$. For her, dirt and disease in hospitals were closely related; hospitals needed to be cleaned up, literally, in order to avoid harming patients' health. Perhaps a further investigation might explain why and how this particular interpretation has remained so powerful to inform much of the more recent debates about hospital infections ${ }^{6}$.

This article, however, is building on a growing interest among historians to overcome the Nightingale narrative of hospital infection and move into the antibiotic era ${ }^{7}$. More specifically, we are particularly interested in the goings-on in hospitals during the first decade or so of the NHS, a time where old meets new, where an ageing hospital infrastructure is taken over by a largely centralised political structure. This is, of course, the time largely associated with the Golden Age of modern medicine, which is characterised by several research breakthroughs and subsequent large-scale clinical deployment of antibiotics ${ }^{8}$. While antibiotics offered a convincing, powerful and cost-effective alternative to infection control old-style, the problem itself turned out to be more of a moving target in as much as the observation of antibiotic resistance began to reframe the problem from very early on ${ }^{9}$. The historical record is of course rather full of euphoria around antibiotics: the US wartime effort so clearly benefited from the arrival of penicillin, and in turn helped to establish the brand: «Thanks to penicillin he will come home», a marketing poster produced by Schenley Laboratories,

\footnotetext{
4. Rosenberg, Charles, ed. Medical care in the United States: medical care before 1940. New York: Garland; 1989; Abel-Smith, Brian. The hospitals 1800-1948. A study in social administration in England and Wales. London: Heinemann; 1964.

5. Nightingale, Florence. Notes on hospitals. London: Longman, Green, Longman, Roberts, and Green; 1863, 1859.

6. Washer; Joffe, n. 2.

7. Condrau, Flurin. Standardising infection control: antibiotics and hospital governance in Britain 1948-1960. Bonah, Christian; Rasmussen, Anne; Masutti, Christoph, eds. Harmonizing 20th century drugs: standards in pharmaceutical history. Paris: Glyphe; 2009, p. 327-339.

8. Bud, Robert. Penicillin: triumph and tragedy. Oxford: Oxford University Press; 2007.

9. Selwyn, n. 3.
} 
can serve as an example for the visual and marketing effects of the war ${ }^{10}$. The Cocoanut Grove nightclub fire in Boston, on 28 November 1942, was another key event which provided the first opportunity for large civilian application of antibiotics, which convinced the medical world as well as wider audiences of the immediate benefits to be had by antibiotics ${ }^{11}$. And finally, the success of the streptomycin trials from 1946 was, unsurprisingly, hugely important to pave the way for a rapid and enthusiastic reception of antibiotics in British medicine ${ }^{12}$. Little wonder then that tales of heroism, discovery and miracles have for a long while dominated the historiography of antibiotics ${ }^{13}$. Indeed, contemporary observers such as the Australian immunologist and later Nobel Prize winner Sir Macfarlane Burnet, quickly assumed that the success of antibiotics had led to a new era in the control of infectious diseases. Surely, he argued, the new drugs would lead to the «virtual elimination of infectious disease as a significant factor in social life» ${ }^{14}$.

Of course such a representation of antibiotics has more recently begun to appear hollow in a society increasingly haunted by fears of drug-resistant «super bugs». The term resistance is the key here: The examination of bacteria and their antibiotic-resistant properties were crucial new ways of thinking favoured by the nascent discipline of hospital microbiologists ${ }^{15}$. It is becoming increasingly obvious that hospital infections became a battleground for deep-rooted conflict and competition between this new discipline and the established clinicians' interests. We aim to analyse this relationship more thoroughly and connect the analysis to understandings of the antibiotic-resistant bacteria and the infections they were causing. Conventional thought understood the main risk to lie with cross-infection of known infectious micro-agents affecting susceptible bodies with weakened

10. Army aidman administers penicillin to battle casualty. Colored advertisement by Schenley Laboratories, Inc., Lawrenceburg, Indiana, August 1944 («Thanks to Penicillin ... he will come home»). [cited 1 Jan 2011 ]. Available at http://explorepahistory.com/images/ExplorePAHistorya0k2r4-a_349.jpg.

11. Saffle, Jeffrey R. The 1942 fire at Boston's Cocoanut Grove nightclub. American Journal of Surgery. 1993; 166: 581-91.

12. Macfarlane, John T.; Worboys, Michael. The changing management of acute bronchitis in Britain, 1940-1970: the impact of antibiotics. Medical History. 2007; 52: 47-72.

13. Lax, Eric. The mold in Dr. Florey's coat: the story of the miracle of penicillin. New York: Holt; 2004.

14. Burnet, Macfarlane. Natural history of infectious disease. Cambridge: Cambridge University Press; 1953, p. ix.

15. Hillier, Kathryn. Babies and bacteria: phage typing, bacteriologists, and the birth of infection control. Bulletin for the History of Medicine. 2006; 80: 733-761; Condrau, n. 7. 
immune systems. The new breed of infections caused by resistant microagents would challenge this view as they were, at least partly, the consequence of medical intervention itself ${ }^{16}$. Following Illich's ideas on iatrogenesis, there is a conceptual connection between the dominant medical intervention in the form of antibiotic drugs and the subsequent disease panorama in the hospital environment. But to what extent was this change in the nature of hospital infections reflected by a new understanding of these infections?

\section{From the hospital environment to the healthy carrier}

The new NHS, often referred to as National Hospital System for the prominence it gave to hospitals within new post-war health care policy, was essentially supposed to draw a line under the problems related to hospital organisation in the nineteenth century and until the interwar period ${ }^{17}$. The main political impetus was, of course, to provide the population with access to medical attention, free at the point of demand. In practice, this largely meant access to hospitals and general practitioners. The hospital as an institution had by now changed quite dramatically, which according to Bud also affected medical practice ${ }^{18}$. Long gone were the days of Nightingale and her call for hospitals to at least cause no harm. By 1948, hospitals were conceptualised as inherently healthy institutions and therefore clean locations, almost perhaps vessels for the emerging scientific medicine ${ }^{19}$. Where the emphasis used to lie on little or no specific medical intervention coupled with long convalescence, hospitals after 1948, faced with a surge in demand for and the increasingly unlimited potential of medical intervention, began to change into high-intervention-short-stay hospitals. Partly this transition was due to real success, as in the declining maternal mortality rates in hospitals, which had been such a plight of hospital medicine since the nineteenth century ${ }^{20}$. One of the leading infection control specialists at

\footnotetext{
16. Illich, Ivan. Medical nemesis: the expropriation of health. New York; Pantheon: 1976.

17. Berridge, Virginia. Health and society in Britain since 1939. Cambridge: Cambridge University Press; 1999.

18. Bud, n. 8, p. 99.

19. Risse, Guenther. Mending bodies—saving souls: a history of hospitals. New York: Oxford University Press; 1999.

20. Loudon, Irvine. Puerperal fever, the streptococcus, and the sulphonamides, 1911-1945. British Medical Journal. 1987; 295: 485-490.
} 
the time, Leonard Colebrook, could conclude in 1955 that puerperal fever caused by streptococcus pyogenes was now almost unheard of ${ }^{21}$.

All this contributed to the representation of the hospital as the best place to get better even if the population might still have harboured some reservations about these institutions. Webster noted that the first decade of the NHS was largely devoted to making do with the existing hospital infrastructure, accommodating growing demand without any major hospital building initiative, which makes the redefinition of hospitals all the more remarkable ${ }^{22}$. Available statistical data suggests that the number of beds in England and Wales rose until 1954 by about 6\%, whilst the number of patients treated in those beds had already risen by around $24 \%$. Over the same time period the number of hospital consultants also rose by about $25 \%{ }^{23}$. This suggests that one important element in the explanation of the relation between hospital infections and infection control during the first decade of the NHS was the increased overcrowding and more intense use of the available hospital infrastructure. The data is certainly mirrored in contemporary complaints that: "Cross infections are as much due to overcrowding in busy wards as to the misuse of antibiotics and faulty technique on the part of the surgeon» ${ }^{24}$. This impression gets even clearer when taking into account the perennial financial difficulties, which the NHS faced right from 1948. Much has been made of the fact that ultimately the economic framing of the NHS was intentionally restrictive. Difficulties with keeping expenditure under control have certainly been a defining feature of the service ${ }^{25}$. Then, as now, the main variables in discussion were staff costs as well as efficient management of the available beds. The tendency to increase bed-usage and general ward population density went alongside recommendations to cut staff numbers with a particular emphasis on nurses and non-clinical housekeeping staff ${ }^{26}$.

\footnotetext{
21. Colebrook, Leonard. Infection acquired in hospital, The Lancet. 1955; 269: 885-891.

22. Webster, Charles. The health services since the war, Vol. 2: Government and health care: the National Health Service 1958-1979. London: HMSO; 1996, p. $16 f$.

23. Report of the Committee of Enquiry into the Cost of the National Health Service. London: HMSO; 1956, p. 301.

24. Scott, J. C. Whose responsibility. Letters to the editor. The Lancet. 1959; 273: p. 578.

25. Barnard, Keith A. Promises, patients and politics: the conflicts of the NHS. In: Barnard, Keith A.; Lee, Kenneth, eds. Conflicts in the National Health Service. London: Croom Helm; 1977, p. 13-25.

26. Vines, H. W. C. Cut in hospital expenditure. Danger of lowered standards. The Times. 31 May 1951, p. 7.
} 
Observers of debates concerning the future of the NHS often note the short-term nature of NHS decisions due to funding situations or administrative regulations. The same can be discovered for the 1950s when commentators in the press pointed out that a patient contracting an infection whilst in hospital remained there for 21 additional days keeping around 3\% of all hospital beds occupied due to nosocomial infections. The cost for this was regarded to be higher than for an effective infection control regime emphasising preventive isolation and thoroughly effective aseptic facilities ${ }^{27}$. To a degree, this notion of avoidable and costly hospital infections is part of the framing of the hospital itself as an inherently clean and healthy institution. But it also points to hospital accounting and governance getting caught up in the debate whether long-term beneficial measures (i.e. infection control) were as easy to justify and get approved as short-term care of patients. Further research is clearly required; suffice to point out here that the introduction of the National Health Service and its implication for hospital governance played at least a contributing role. The hospitals under the NHS were not simply coping with occasional «infection accidents»; they appear to become important transmission vectors for nosocomial infections.

But it is, of course, a fundamental misreading of history to assume that these problems have only recently been revealed. It is increasingly accepted that sustained doubts and uncertainties have accompanied the increased use of antibiotics in the battle against hospital infections right from the $\operatorname{start}^{28}$. It would be quite fallacious to suggest that the ideal of a future utopia where infectious disease had been eradicated was the unchallenged aim of medical science even at the dawn of the antibiotic era. Particularly relevant for the early history of antibiotics, a picture of difficulties, vested interests and uncertainty is emerging that juxtaposes the tales of the Magic Bullet $^{29}$. But it seems that much uncertainty was overcome by the success of the clinical trials conducted by the MRC and, later, by the wider application of the clinical trials regime as a socio-medical technology. This latter point is particularly important to understand the sudden burst of interest for

27. Medical Correspondent. Surgical wound infections. Hospital sepsis on the increase. The Times, 26 Sept. 1960, p. 7.

28. Bud, n. 8.

29. Yoshioka, Alan. Streptomycin in postwar Britain: a cultural history of a miracle drug, biographies of remedies. In: Gijswit-Hofstra, Marijke; Tansey, Tilly, eds. Biographies of remedies. Drugs, medicines and contraceptives in Dutch and Anglo-American healing cultures. Amsterdam: Rodopi; 2002, p. 203-228. 
antibiotics and the general mood swing toward such medication from the late 1940s, helped along by well-publicised application of the regimes in Britain, India and elsewhere ${ }^{30}$. We can only refer the reader to interesting research suggesting that the organisational innovation of clinical trials appears to be as crucial as the biomedical importance ${ }^{31}$. It was unquestionably the case that this new form of evidence generation sustained an amazing level of confidence in antibiotics; but the question as to how the new confidence translated into clinical practice remains only partly answered ${ }^{32}$. In the case of bronchitis, a persuasive argument has been presented which emphasises the practicability of antibiotics noting, though, that the first wave of clinical practice was largely confined to the hospital and only increasing availability of oral penicillin began to shift intervention to GPs ${ }^{33}$. This puts the emphasis for the early years of antibiotic practice firmly on the hospital.

What, then, governed the use of antibiotics in the hospital? At the time, the main battle lines were drawn between a «militaristic» approach which aimed to wipe out infections with the use of antibiotics and a more ecological understanding that stressed infection control if not management over eradication in order to maintain the dynamic balance between man and micro-organisms ${ }^{34}$. It was argued that eradicating any particular microorganism would only result in other possibly more pathogenic microbes moving in to fill the void. In any case, it was suggested the eradication of disease would in fact leave humanity in a precarious position exposed without defence should new micro-organisms be introduced into the world $^{35}$. In a wide ranging discussion, Julian Huxley denounced the ideal of

30. Amrith, Sunil. In search of a «magic bullet» for tuberculosis: South India and beyond, 1955-1965. Social History of Medicine. 2004; 17: 113-130; Valier, Helen. At home in the colonies: the WHO-MRC trials at the Madras Chemotherapy Centre in the 1950s and 1960s. In: Condrau, Flurin; Worboys, Michael, eds. Tuberculosis then and now: current issues in the history of an infectious disease. Montreal: McGill-Queens University Press; 2010; p. 213-234.

31. Timmermann, Carsten; Valier, Helen. Clinical trials and the reorganization of medical research in post-Second World War Britain. Medical History. 2008; 42: 493-510; Marks, Harry. The progress of experiment: science and therapeutic reform in the United States, 1900-1990. Cambridge: Cambridge University Press; 1997.

32. Condrau, n. 7.

33. Macfarlane; Worboys, n. 12, p. 58.

34. Wolstenholme, Gordon, ed. Man and his future. London: Churchill; 1963.

35. Koprowski, Hilary. Future of infections and malignant diseases. In: Wolstenholme, n. 34, p. 196216. See also Dubos, René. The dreams of reason: science and utopias. New York: Columbia UP; 1961. 
eradication as an «ecological absurdity» ${ }^{36}$. Moreover, he did so in terms that encompassed not only the eradication of disease associated with medical discourse but also in relation to the ideal of the eradication of pests in the agricultural context. Of course, this needs to be read in conjunction with eradication strategies against infectious diseases, with the WHO campaign against malaria being of particular prominence ${ }^{37}$.

We want to simply argue here that this elision between understandings of infectious disease causing micro-organisms and wider ecological concepts is illustrative of the way in which antibiotics and micro-organisms were understood in clinical practice at the time. Whilst many clinicians did view antibiotics as a means to eradicate micro-organisms, others understood antibiotics in a far more complex manner that drew upon emerging ecological understandings of the world. These new ways of understanding the problem of antibiotics and bacteria also contributed to the emergence of new analytical perspectives regarding the problem of transmission. The concept of a «healthy» carrier - an individual who harboured and transferred pathogenic micro-organisms without showing signs of infection- was of course well known already to previous generations of British bacteriologists ${ }^{38}$. The whole idea goes back to classic writing by nineteenth century bacteriologists, most notably of course by Robert Koch in his work on typhoid ${ }^{39}$. It complemented the notion of an undetected infectious case in the wild, which has been the primary focus of tuberculosis control efforts. During the 1930s, the concept of the healthy carrier became used as an explanatory framework to understand the emergence and spread of infection within hospitals. The development of the idea of the carrier allowed a shift of the epidemiologic

36. Koprowski, n. 35, p. 236.

37. Packard, Randy M. «No other logical choice»: global malaria eradication and the politics of international health in the post-war era. Parassitologia. 1998; 40 (1-2): 217-29; Stapleton, Darwin H. Lessons of history? Anti-malaria strategies of the International Health Board and the Rockefeller Foundation from the 1920s to the era of DDT. Public Health Rep. 2004; 119 (2): 206-215.

38. See for example Anon. Carriers in infectious diseases. The Lancet; March 31 ${ }^{\text {st }} 1923$, p. 661-2; Walzer Leavitt, Judith. «Typhoid Mary» strikes back: bacteriological theory and practice in early twentieth-century public health. Isis. 1992; 83: 608-629.

39. Mendelsohn, John A., «Like all that lives»: biology, medicine and bacteria in the age of Pasteur and Koch. History and Philosophy of the Life Sciences. 2002; 24: 3-36; Gradmann, Christoph. Robert Koch and the invention of the carrier state: tropical medicine, veterinary infections and epidemiology around 1900. Studies in History and Philosophy of Science Part C: Studies in History and Philosophy of Biological and Biomedical Sciences. 2010; 41: 232-240. 
attention towards case detection as defined by the carrier state as opposed to a definition of case detection by disease state. This shift had already started to occur in tuberculosis control due to declining disease prevalence, which also helped to further popularise the idea of patient zero ${ }^{40}$. These concepts ultimately enabled individual carriers to be held responsible for an outbreak of infection as opposed to a hospital environment more generally ${ }^{41}$. By the post-war period, such concerns had opened up a new spatiality for study, that of the carrier and its interactions with the wider physical environment within and outside of hospitals ${ }^{42}$.

In approaching staphylococci infection, bacteriologists identified healthy carriers as the primary source of cross infection. But they were not simply concerned with individuals, rather, overcoming the straightforward notion of the patient zero, staphylococci were found to reside primarily within the anterior nares of the nose of individual carriers from where they were spread to the skin, clothes, and the wider hospital environment ${ }^{43}$. Later attention shifted to so-called faecal carriers ${ }^{44}$. It was soon agreed that carriers of staphylococcal bacteria played an important albeit little understood role in the spread of infection within hospitals. Moreover, it was also frequently reported that carrier rates in the hospital differed dramatically from the community as a whole - to the extent that the former could be found to be double the rate of the latter ${ }^{45}$. Consequently, efforts to control hospital infections shifted from prioritising the cleanliness of the physical environment to a focus on the bacteriological load of the individual. In an effort to reduce the carriage of problem micro-organisms, trials of antibacterial snuffs and creams which incorporated penicillin were undertaken as early as $1940^{46}$.

\footnotetext{
40. Barnes, David S. Targeting patient zero. In: Condrau; Worboys, n. 30, p. 49-71.

41. Anon. A streptococcal carrier. The Lancet. 1931; 218: 808-809.

42. Duguid, J. P.; Wallace, A. T. Air infection with dust liberated from clothing. The Lancet; 1948, 252: 845-849.

43. Gould, J. C. The effect of local antibiotic on nasal carriage of staphylococcus pyogenes. Journal of Hygiene. 1955; 53: 379-385.

44. Broudie, J.; Keer, Mary R.; Sommerville, T. The hospital staphylococcus: a comparison of nasal and faecal carrier states. The Lancet. 1956; 267: 19-20.

45. Broudie; Keer; Sommerville, n. 44.

46. Delafield, M. E.; Straker, E.; Topley, W. W. C. Antiseptic snuffs. British Medical Journal. 1941; 1: 145-150; Hobbs, B. C.; Carruthers, H. L. Sycosis barbae: serological types of staphylococcus pyogenes in nose and skin and results of penicillin treatment. The Lancet. 1947; 250: 572-574; Moss, B.; Squire, J. R.; Topley, E. Nose and skin carriage of staphylococcus aureus in patients receiving penicillin. The Lancet. 1948; 251: 320-325.
} 
These early studies were found to be effective, but there is little evidence to suggest whether the practice was adopted on a wider scale. Still, their importance stems from the fact that they appear to have paved the way for the deployment of antibiotics in a prophylactic rather than therapeutic way.

By the 1950s penicillin had, of course, ceased to be the antibiotic of choice for the treatment of staphylococci due to prevalent resistance, but little advance had been made on the understanding of the role of the carrier in hospital cross infection ${ }^{47}$. In 1954 two Edinburgh bacteriologists, J. C. Gould and W. S. A. Allan, attempted to establish a sure link between carriers of staphylococcus pyogenes outbreaks of infection within a local general hospital of 170 beds $^{48}$. In order to at least point to complex interrelations between hospital based research and private enterprise, it is worth mentioning that oxytetracycline utilized for this study was Pfizer's «Terramycin», which had been supplied gratis by the company. Gould and Allan embarked upon a thorough sweep of the hospital environment collecting samples of staphylococcus pyogenes from ward dust, blankets, operating theatres and the general environment and contrasted these with samples taken from the anterior nares of carriers in order to identify the predominant source of infection in patients. Phage typing revealed that staphylococcus pyogenes found in the physical environment was responsible for only a minority of infections in comparison to that found in carriers. Consequently, a ten day trial was undertaken applying a oxytetracycline-based cream intranasally to identified carriers within the hospital. This was found to substantially reduce the carriage rate for staphylococcus pyogenes for a period that lasted three months and was mirrored by a similar reduction in hospital infections. Whilst a demonstrable link between carriers and hospital infections was welcomed, the proposal to use antibiotics of therapeutic value such as penicillin or oxytetracycline for routine prophylaxis was for some a risky strategy ${ }^{49}$. Arrays of alternatives were investigated, utilizing antibiotics such as Neomycin, Naspetin and Soframycin in various combinations of sprays and creams, some of which are still in use for the purpose today.

47. Rountree, Phyllis Margaret; Freeman, Barbara M.; Barbour, R. G. H. Nasal carriage of staphylococcus aureus in the general population and its relationship to hospitalization and to penicillin therapy. Medical Journal of Australia. 1954; 12: 457-460.

48. Gould, J. C.; Allan, W. S. A. Staphylcoccus pyogenes cross-infection: prevention by treatment of carriers. The Lancet. 1954; 264: 988-989.

49. Stewart, G. T. Staphylococcal carriers. The Lancet. 1954; 264: 1175. 
Yet consensus was difficult to achieve. For every report claiming to conclusively demonstrate the success of a specific treatment, a counter claim or criticism would quickly follow ${ }^{50}$. In any case, due to a lack of understanding of the mechanisms of antibiotic resistance and the general complexity of tracing the origins of cross infection, all such recommendations remained cautious and indefinite. Ultimately this led the clinicians, whilst responsible for taking action to control cross infection, unable to recognise any clear evidence with which to determine a suitable course of action. As such, it was frequently noted that in practice clinicians, surgeons and nurses remained «apathetic or frankly cynical» as to best practice in controlling the carrier as a vector of cross infection ${ }^{51}$. The tentative nature of published studies combined with their focus on bacteriological investigations brought about a caesura between the assertions of bacteriologists and the general practice of clinicians. This prevented the findings of the former being applied with certainty and rigorously (if at all) by the latter. This mirrors how clinicians were told on the one hand to use antibiotics whilst they lasted and on the other not to use antibiotics excessively, and is yet another example of difficulties related to the communication of and interaction between scientific evidence and clinical practice before the age of evidence-based medicine ${ }^{52}$.

Social practicalities made yet more difficult the practical control of carriers. It was suggested that when a person suffered obvious staphylococcal lesions it could be taken for granted (without invasive swabbing) that they would be carriers of the bacterium either nasally, perineally, or more likely both ${ }^{53}$. Action in such a case was thought particularly important if the person was a surgical patient, as a number of studies indicated such patients were far more likely to become infected in the postoperative period

50. See for example Stratford, Bryan; Rubbo, Sydney D.; Christie, R.; Dixson, Shirley. Treatment of the nasal carrier of staphylococcus aureus with Framacytin and other bacterials. The Lancet. 1960; 276: 1225-1227; Rammelkamp, Charles R. Treatment of nasal carriers of staphylococci. The Lancet. 1961; 277: 112; Rubbo, Sydney D. Treatment of nasal carriers of staphylococci. The Lancet. 1961; 277: 561-562.

51. Green, Kenneth $\mathrm{G}$. The role of the carrier in staphylococcal disease. The Lancet. 1961; 277: 921-924.

52. Claridge, Jeffrey A.; Fabian, Timothy C. History and development of evidence-based medicine. World Journal of Surgery. 2005; 29: 547-553.

53. Hobbs; Carruthers, n. 46; Valentine, F. C. O.; Hall-Smith, S. P. Superficial staphylococcal infection. The Lancet. 1952; 260: 351-354; Tulloch, L. G. Nasal carriage in staphylococcal skin infections. British Medical Journal. 1954; 2: $912 f$. 
than non-carriers ${ }^{54}$. However, treating staff was far more problematic routine application such as that suggested by Gould and Allan was found unfeasible as it caused «staff unrest». Even with targeted treatment aimed at specific problem cases best practice remained unclear, particularly as once the period of nasal treatment ended re-infection would inevitably follow. Some rejected the goal of the targeted reduction of carriage in itself as it would fail to break the staphylococcal «infection cycle» within the hospital. Such arguments stated that the countering of nasal carriers with creams and sprays could only be a temporary measure as re-infection would surely follow from alternative reservoirs of infection, whether this be within the individual (such as the perineum) or from other individuals (through the patient's wounds becoming infected) or the wider environment ${ }^{55}$. It was thought necessary for staff being treated to agree to dry clean their clothes, wash only using anti-bacterial soap, and ideally be sent on holiday away from the hospital in the hope of becoming colonised by a «civilian» strain of staphylococcal ${ }^{56}$.

Furthermore, the perineum carrier was particularly difficult to gauge much less control due to the social impracticality of gaining regular access to this site particularly amongst staff ${ }^{57}$. This was all highly impractical, and as long as some reports questioned the efficacy of treating carriers in terms of reducing infection rates, this was unlikely to be adopted in practice and resulted in the carrier as a new figure, situated between the norm and the abnormal, problematic for the potential to become pathologic ${ }^{58}$.

Nonetheless, the debate over carriers revealed a very real implicit assumption that the hospital environment was in some way both important

54. Williams, R. E. O. Nasal staphylococci and sepsis in hospital patients. British Medical Journal. 1959; 2: 658-662; Weinstein, H. J. The relation between the nasal-staphylococcal-carrier state and the incidence of postoperative complications. New England Journal of Medicine. 1959; 260: 1303-1308.

55. Gillespie, W. A. staphylococcal cross-infection in surgery: effects of some preventive measures. The Lancet. 1959; 274: 781-784; Hare, R.; Ridley, M. Further studies on the transmission of staph. aureus. British Medical Journal. 1958; 1: 69-70.

56. Green, Kenneth $\mathrm{G}$. The role of the carrier in staphylococcal disease. The Lancet. 1961; 278: 921-924, mainly 922

57. Ridley, M. Perineal carriage of staph. aureus. British Medical Journal. 1959; 1: 270-273.

58. For example Henderson, R. J.; Williams, R. E. O. Nasal disinfection in prevention of post-operative staphylococcal infection of wounds. British Medical Journal. 1961; 2: 330-333; Williams, J. R. B.; Maughan, E. C. S. Talbot. Hospital outbreak of cross-infection due to staphylococcus pyogenes phage type 80. British Medical Journal. 1959; 1: 1374-1378. 
and different to the environment of the wider community, the latter sometimes tellingly referred to as «civilian». Indeed, it became standard advice for General Practitioners, if faced with what had been common problems such as styes, boils and others staphylococcal skin conditions, to enquire whether the patient or his immediate contacts had recently been hospitalized $^{59}$. The hospital environment had become one of the risk factors worth investigating when taking a medical history. Often the hospital environment was viewed as being more dangerous in terms of the microbes it harboured than conventional domestic environments ${ }^{60}$. And investigations into the transmission of staphylococcal infections led to the discovery of the new-born baby as one of the primary vectors of transmission $^{61}$.

\section{Conceptualising the control of hospital infections}

What then might we mean by an ecological orientation toward antibiotic use? The Oxford English Dictionary defines ecology as «that branch of biology which deals with the relations of living organisms to their surroundings, their habits, their modes of life, etc.» This was certainly the meaning that Julian Huxley implied when he labelled the eradication of infectious disease an «ecological absurdity» ${ }^{62}$. Huxley was not thinking here of eradicating «disease» as such but of eradicating the causative organism and this, he knew only too well, would merely open up a space in nature that might be filled by organisms equally pathogenic to man. Even if it proved possible to construct a world where man lived in harmony with the micro-organisms about and within him, there was no means to protect the future of humanity from the devastating consequences of a chance mutation creating a new pathogenic organism. To suggest nature was in a sense static was therefore foolish to a biologist such as Huxley. All organisms lived in a dynamic relationship to all other organisms as well as the wider environment. Moreover, both

\footnotetext{
59. Green, n. 56, p. 923.

60. See for example Williams, R. E. O. Epidemiology of hospital infection: synthesis. In: Williams, R. E. O.; Shooter, R. A., eds. Infection in hospitals epidemiology and control. Oxford: Blackwell; 1963, p. 189-193.

61. Isbister, C. Staphylococcal infection in infancy. Medical Journal of Australia. 1959; 46: 629-633; Hillier, n. 15.

62. Koprowsky, n. 35; Dubos, n. 35.
} 
the organisms themselves and the ecological relationships were subject to change over time - this was the basis of neo-Darwinian evolution. Whilst knowledge of evolutionary theory was relatively unimportant to the work of the clinician it was fundamental to the bacteriologist interested in the question of resistance to antibiotics. The adaptability of bacteria when in the presence of poisonous substances had been recognised long before the advent of antibiotic therapy. One of the earliest articles on the subject appeared in the first volume of the Annales De L'Institut Pasteur in $1887^{63}$. By the 1930s bacterial «resistance» to antimicrobial substances such as the sulphonamides was well established ${ }^{64}$. Consequently, one of the earliest studies on penicillin assessed its effectiveness on a strain of streptococci known to be resistant to the sulphonamides. The same investigation also sought to assess the potential of bacteria to «acclimatise themselves» to penicillin by cultivating a strain of staphylococcus aureus over a period of months in the presence of incrementally increased quantities of penicillin. After 15 weeks a «resistant» strain had emerged that could multiply in the presence of a concentration of penicillin a thousand times greater than that which had originally inhibited the growth of the parent strain ${ }^{65}$. Penicillin resistant staphylococcus aureus would thus have to be recognised as a laboratory created microagent, before it became a problem in the wild. Further research is required to establish whether there was any link between laboratory analysis and hospital outbreaks, but with the long history of suspicion against medical malpractice in infectious diseases, such questions appear to be promising on more than one level.

In point of fact a conceptual terminology, if not a microbiological explanatory framework, existed to accommodate observations of bacteria surviving within a penicillin-rich environment. Antibiotics as literal «destroyers of life» would be expected to meet with some form of «resistance» according to known biological principles - not least that of natural selection. Moreover, this understanding of resistance assumed an ecological view of micro-organisms - indicative in the word «acclimatise»- predicated upon relations to environment. This is not the space to engage in an entymological

63. Kossiakoff, M. G. De la propriété que possèdent les microbes de s'accomoder aux milieux antiseptiques. Annales de I'Institut Pasteur. 1887; 1: 465-476.

64. See for example MacLean, Ian H.; Rogers, Keith B.; Fleming, Alexander. M. \& B. 693 and pneumococci. The Lancet. 1939; 233: 562-568.

65. Abraham, E. P. Further observations on penicillin. The Lancet. 1941; 238: 177-189. 
analysis of the meaning of the term resistance; suffice to say that analogies between campaigns against antibiotic resistant microbes and political representations of resistance seem rather compelling ${ }^{66}$. Indeed, bacteriologic research has a long record of a largely militaristic and political rhetoric and collaboration ${ }^{67}$. This has certainly been instrumental for the popularization of bacteriological knowledge ${ }^{68}$. However, when it came to antibiotic use, many bacteriologists were predetermined to an ecological framework. Their emphasis on the wider environment pointed to a dynamic and relational understanding of disease, microagent and environment. The environment became central to the understanding of antibiotic use for practical reasons also, not least the assumed connection between specific environments (the hospital) and specific resistant micro-organisms (staphylococcus aureus). Early concern over antibiotic-resistant bacteria focussed predominantly upon the staphylococci as a direct result of their being seen to be the predominant resistant bacteria encountered in day to day hospital practice. From the late 1940s detailed reports of increasing frequencies of resistant staphylococci infections in hospitals began to appear ${ }^{69}$. By 1956 these reports led the British Medical Journal to identify resistant staphylococci infection as the «most disquieting feature of present-day hospital practice», second only to the possibility that staphylococci virulence had been inadvertently invigorated by antibiotics ${ }^{70}$. As resistant staphylococci were increasingly found to be responsible for infection, this suggested to some the possibility that such bacteria might possess a greater capacity for epidemic spread and that antibiotic use risked producing new and more threatening infections ${ }^{71}$. Such speculation was possible as the molecular means and mechanisms by which bacteria resisted lethal substances remained uncertain. Hospital

66. Sarasin, Philipp. Infizierte Körper, kontaminierte Sprachen. Metaphern als Gegenstand der Wissensgeschichte. In: Sarasin, Philipp, ed. Geschichtswissenschaft und Diskursanalyse. Frankfurt am Main: Suhrkamp; 2003, p. 191-230.

67. Gradmann, Christoph. Invisible enemies: bacteriology and the language of politics in imperial Germany. Science in Context. 2000; 13: 9-30.

68. See for a contemporary polemic: Sarasin, Philipp. Anthrax. Bioterror as fact and fantasy. Cambridge MA: Harvard University Press; 2006.

69. Barber, Mary. Staphylococcal Infection due to Penicillin-Resistant Strains. British Medical Journal. 1947; 2: 863-865; Barber, Mary; Rozwadowskadowzenko, M. Infection by penicillin-resistant staphylococci. The Lancet. 1948; 255: 641-644.

70. Anon. Antibiotics versus staphylococci. British Medical Journal. 1956; 2: 217-218.

71. Howe, C. W. Postoperative wound infections due to staphylococcus aureus. New England Journal of Medicine. 1954; 251: 411-417. 
bacteriologists were at liberty to investigate resistant micro-organisms, seeking both practical solutions and theoretical explanations whilst speculating freely. Yet their investigations were somewhat limited to the macro-environment rather than the molecular.

These debates and limitations contributed to the bacteriologist moving to the forefront of hospital management and hospital-based medical care becoming a key arbiter for the future of medical practice. Moreover, bacteriological investigations were predicated on a dynamic and ecological understanding of micro-organisms. Bacteriologists understood the hospital environment as problematic in two interrelated ways. First, it harboured potentially pathogenic micro-organisms, and second it was the vector by which pathogens were transmitted to susceptible hosts. But what was this «hospital environment»? In part it covered the physical environment of the hospital in its totality, from walls, floors, beds and furniture to curtains, clothing, medical equipment and everything in between. But this, it was recognised with ease, represented the misguided focus of the old hospital reform debate: it had become increasingly obvious that cleaning hospitals was not enough to fend off hospital infections. Rather, whilst the physical environment could harbour micro-organisms (particularly if damp) it was not in itself considered the primary source of such pathogens but rather a vector of transmission. Based on our analysis, the main source of microorganisms was the human beings that inhabited the hospital environment and thereby formed a part of it. Neither Nightingale's nurses cleaning day and night nor the nauseating smells of Lister's carbolic acid sprays remained an appropriate measure when the meaning of the term environment had so fundamentally shifted.

In contrast to bacteriologists, clinicians possessed a different orientation that shaped their understanding and practical use of antibiotics. This is not to say that clinicians were ignorant of or disbelieving in the danger of antibiotic resistance. On the contrary, writings in the medical press at this time demonstrate a thorough understanding of the temporal utility of antibiotics in view of the ability of bacteria to develop drug resistance. Indeed, it was knowledge of the temporality of antibiotic effectiveness that motivated clinicians' resorting to the old adage «use the new drug while it still acts» - a position partly endorsed in an article on the «Rational Use of Antibiotics» published in the Lancet in 1952. This article noted that the «need is great, though the time is not right, for a simple guide to the intelligent 
use of microbial drugs ${ }^{72}$. The need was indeed great due to the ordinary clinician being bewildered by the complexity of antibiotic therapy as the number of available drugs multiplied whilst it appeared the sensitivity of bacteria to antibiotics was ever decreasing. The time was not ripe as neither clinician nor bacteriologist could reliably demonstrate the best means to manage antibiotic use in order to maintain the new drugs efficacy. There was a substantial lack of understanding as to the mechanics of the emergence of resistance at this time that resulted in multiple and conflicting claims as to the best practical use of antibiotics flooding the medical press. A poignant example of the complexity faced by clinicians can be found in the practice of combining antibiotics in what became known, and not insignificantly, as «shotgun therapy». Reference to shotgun prescriptions is as old as Ehrlich's recommendation of shooting microbes with magic bullets - a notion that whilst largely metaphorical in the language of the bacteriologist became almost literal in the minds of practising clinicians demonstrating their adherence to the militaristic idea of eradication of disease ${ }^{73}$. Combining different antibiotics was quickly touted as a means to improve therapeutic efficacy whilst inhibiting the emergence of resistant bacteria ${ }^{74}$. However, it remained far from clear which combinations proved synergistic and which antagonistic. A review of the subject published in 1957 concluded that antibiotic combination therapies were «insufficiently studied and assessed» and therefore hoped each «doctor who may have occasion to prescribe an antibiotic combination will carefully examine and assess the evidence before he does so» ${ }^{75}$. A few years later such hopes were rebutted on the grounds that there was «no evidence to assess because the present practice of chemotherapy develops largely by trial and error and under the influence of local fashion» ${ }^{76}$. Instead, it was suggested that antibiotic combination could only be guided by each clinician constructing and refreshing at intervals their own set of principles based upon authoritative reviews and personal experience. Without comprehensive clinical trials to balance understandings of the activity of bacteria derived from laboratory and clinical

\footnotetext{
72. Rational use of antibiotics. The Lancet. 1952; 260: 173-174, mainly 173.

73. The congress of medicine. The Times. 13 Aug 1913; 40289: 3.

74. Daniels, Marc; Bradford Hill, A. Chemotherapy of pulmonary tuberculosis in young adults. British Medical Journal. 1952; 1: 1162-1168.

75. Antibiotic combinations. The Lancet. 1957; 270: 177-178, mainly 178.

76. Lacey, B. W. The rationale and management of combined therapy. British Medical Bulletin. 1960; 16: 42-46, here mainly 42.
} 
experience, a programme for the rational use of antibiotics would remain an improbable dream due to the innumerable divergent views on every aspect of antibiotic use which could be found in the literature. Moreover, without clear understandings of the consequences of combination therapy there was a very real danger its use might encourage rather than discourage the emergence of resistant organisms ${ }^{77}$. For this reason, the Lancet could claim within the same article that there was «much sense» in the adage «use the new drug whilst it lasts» and at the same time stipulates that the indiscriminate use of antibiotics should be deterred ${ }^{78}$. In such an atmosphere of mixed messages, it is understandable that the clinician would focus on actions to resolve the problems of the present rather than hypothesise on the consequences such actions might have for the future. An explanation for the choices made under this uncertainty concerning the rational use of antibiotics would have to come from different timelines: antibiotic resistance was a problem that usually occurred in the future, whereas fending off an already existing infection or preventing the occurrence in a hospital ward was regarded as a pressing need of the present. It seems of fundamental importance to understand how the different professional groups chose to work to such different timelines. Interestingly, it was widely recognised that the environment alongside the host, pathogen and antibiotic formed the four interrelated factors of chemotherapy ${ }^{79}$.

\section{Conclusion}

The debate surrounding the appropriate use of antibiotics reveals the complex relationship between hospital, the medical sciences and clinical practice. Challenging the view that the hospital is a more or less neutral location of medical innovation and practice, our analysis contributes to an emerging historiography which sees the hospital as an arena where professional battles between research, medical practice and public health interests were being contested. These are predominantly concerned with practice -it is not the research which is debated so fiercely, but the practical

77. Garrod, L. P. The erythromycin group Of antibiotics. British Medical Journal. 1957; 2: 57-63.

78. Rational, n. 72, 173-174.

79. Lowbury, E. J. L. Clinical problems of drug-resistant pathogens. British Medical Bulletin. 1960; 16: 73-78. 
implementations of research findings, which firmly entrenches our analysis within the pre-history of evidence-based medicine.

Important albeit often overlooked elements in these discussions were the conceptual assumptions about antibiotics put forward by microbiologists and clinicians. Whilst the latter saw antibiotics as part of their arsenal in their quest for medical success, the former began to understand the increasingly difficult balance between antibiotics and their development within a context of ever-adapting hospital infections. Not so much viewed as the price to pay, for the microbiologists of the immediate post World War II era, nosocomial infections represented the true test for the longevity of antibiotics as an effective and useful medical intervention. This reveals an underlying tension between innovation and discovery, versus the long-term management of a useful but inherently limited resource such as antibiotics.

During this debate, the epidemiology of hospital infections got reconfigured and moved away from studying the material hospital environment to put the emphasis on the healthy carrier of staphilococcal strains. From a historian's point of view this is significant because it successfully allowed detaching the hospital from the list of potential culprits. When Florence Nightingale fought for hospitals «to do the sick no harm», she could battle for institutional reform. The microbiologists after the war had no such luxury as they increasingly focused on individuals and their bodies, with preventative measures being increasingly targeted at patients and staff and their respective habits. Our analysis contributes to a growing body of research which redefines the boundaries of hospital infections. Contrary to many modern political or media representations, the control of nosocomial infections does not hinge on easy solutions such as hospital deep cleaning operations or staff washing their hands, but remains fundamentally linked to all facets of medical practice and intraprofessional coordination. The multi-disciplinary teams, of which there is so much talk in infection control, require firm leadership and structures of accountability, which are not easy to maintain under the conditions of day to day management of hospitals and patients.

Perhaps an argument could be made that ours is a British story. The NHS has probably emphasised the problem through its fiscal austerity as well as its non-discriminatory access regime. It appears to us that the NHS has become hostage to its own fortune: keeping the organisation and management of the health service in the political spotlight has provided the historian with the data necessary to reconstruct the problem, while other, less 
politicised health care organisations do not and would not make similar data accessible. But we also think that the story we have begun to tell is a story of Western healthcare, where the very success of its innovations forms the basis for its perennial structural crisis. The lesson of the history of hospital infections thus lies in a more fundamental reflection on hospital cultures, antibiotic prescription practices and the fostering of an interdisciplinary spirit among the professional groups living and working in the hospital. 